\section{Gloom at the top}

Details of Britain's Science Budget, were disclosed last week. Chris Sherwell reports

IF THERE is despondency in Britain's science community this week, no one should be surprised. There is gloom at the top. Details of the Science Budget given last week by the Advisory Board for the Research Councils (ABRC) covered allocations for the 1977-78 financial year just begun and guidelines for the four additional years to 198182. The figures are much as expected (see table), but then sliding down a curve is no more comfortable for being warned of it in advance, particularly when (as now) the low point remains invisible.

Outlining the trends, the ABRC chairman, Sir Frederick Stewart, said the 1977-78 Science Budget of nearly $£ 249$ million (1977 prices) represented a cut in real terms of more than $3 \%$ on the 1976-77 budget. The government's public expenditure White Paper published in February indicated a budget of $£ 216$ million for the year, but this was at 1976 prices. Both figures included an additional $£ 6$ million to cover the increased cost of post-graduate tuition fees in 1977-78, and this too tended to make the trend less steady than it actually was.

Discussing the guidelines, Sir Frederick drew on the White Paper's own emphasis on the provisional character of figures for the years 1980 81 and 1981-82 in describing them as "very provisional"; they were intended to provide each of the councils with a broad basis for planning. The guidelines did, however, represent a continuation of the protection of the "small and medium sciences" at the expense of high energy physics, astronomy and space.

Thus the Science Research Council (SRC) faces a $1.7 \%$ contraction annually, a cut which Sir Frederick said could amount to more than $20 \%$ over a five-year period with vexed problems like 'salary creep'-the consequence of maintaining ageing research staffs on graded incremental salary scales.

On the other hand, in line with the SRC's and the ABRC's previously announced intentions, support for engineering is to grow substantially, and is in fact the only part of the budget to show a marked increase. How much this increase will prove to be by the end of the period was uncertain, Sir
Frederick said, but it "might amount to a $60 \%$ expansion". The SRC chairman, Sir Sam Edwards, stressed, however, that even a modest effort in favour of engineering would represent a large increase on the support that it received before. He was also quick to dismiss suggestions that the perceived need to support work 'relevant' to the country's industrial needs diluted the SRC's task of supporting basic research: the SRC's support for engineering, he insisted, was for basic research, just as it was in other fields.

Sir Sam described the reductions in support for big science as more serious than the figures suggested. Much of the SRC's expenditure went on international subscriptions, for example to CERN, and that meant that the effective decline in support for domestic activity might be more than $50 \%$, not $20 \%$. This, he said, would happen at a time when the pressure was on for Britain to participate fully rather than merely "tick over"; there were many projects which ought to be done "bigger, better and faster" than they were being done.

The position on international subscriptions clearly remains precarious. The SRC has the money to pay them this year, Sir Sam said, but if the pound collapsed again, "I don't know where we are"; the government had not given an open-ended commitment, and no bailing out could be guaranteed if that again proved necessary. As for the SRC's maintenance of a "minimum viable level of support" for big science -a concept outlined last year as the cuts really began to bite-Sir Sam confirmed that the big science community already believed that that level had been breached. The council's view, he indicated, was that it was extremely difficult to judge precisely what that level was.
Like the guidelines, the allocations of the 1977-78 budget reflect the policy of redeployment away from big science, though as usual the lion's share necessarily goes to SRC. Also given are figures for research commissioned by government departments under the Rothschild arrangements for applied research.

For the Agricultural Research Council (ARC) income from commissioned research, representing $55 \%$ of its total budget, will grow at $0.6 \%$, but this will only contain the 'salary creep'. The Medical Research Council (MRC) faces more of a problem. As part of the general cuts in government expenditure the Department of Health has at short notice cut by $10 \%$ its commissioned research. The Natural Environment Research Council expects to have its funds maintained from the various departments (Agriculture, Industry, Energy, Environment), but anticipates cuts in the future. Against all this, Sir Frederick said that he saw no evidence that the spending departments were taking their funds elsewhere, a possibility Rothschild originally foresaw.

There is no doubt that the research councils face problems. Apart from the usual agonising difficulties of deciding priorities and, more notably, starting new projects, they agree that their main problem is nothing less than "keeping science alive" in Britain. In that they were echoing the views contained in the recent annual survey from the University Grants Committee (UGC), which with the research councils constitutes the Dual Support System for university research.

"We are deeply concerned", said the UGC, "about the deterioration of research capabilities in the universities... We will continue to watch the developing situation with anxiety". Those words might well have been repeated last week by the research councils for the whole of Britain's civil science effort.

\begin{tabular}{|c|c|c|c|}
\hline \multicolumn{4}{|c|}{ Science Budget: Allocation and Guidelines } \\
\hline & $\begin{array}{l}\text { £ million }{ }^{1} \\
1977-78\end{array}$ & $\%$ Share & $\begin{array}{c}\% \text { p.a. } \\
1978-79 \text { to } 1981-82\end{array}$ \\
\hline $\mathbf{A R C}$ & 20.4 & 8.2 & 1.9 \\
\hline MRC & 42.3 & 17.0 & 1.6 \\
\hline NERC & 27.2 & 10.9 & 2.5 \\
\hline SRC & 138.0 & 55.4 & -1.7 \\
\hline SSRC & 14.6 & 5.9 & 1.9 \\
\hline $\begin{array}{l}\text { British Museum } \\
\text { (Natural History) }\end{array}$ & 4.2 & 1.7 & 0.0 \\
\hline Royal Society & 2.2 & 0.9 & 1.0 \\
\hline Total & 248.9 & 100 & \\
\hline
\end{tabular}

${ }^{1}$ Figures are at 1977 prices. They exclude estimated receipts of $£ 52.5$ million from commissions from government departments (ARC $£ 24.2$ million; MRC $£ 11.7$ million; NERC $£ 16.6$ million) 